\title{
Entre o funcional e o lúdico: a camisinha nas campanhas de prevenção da
}

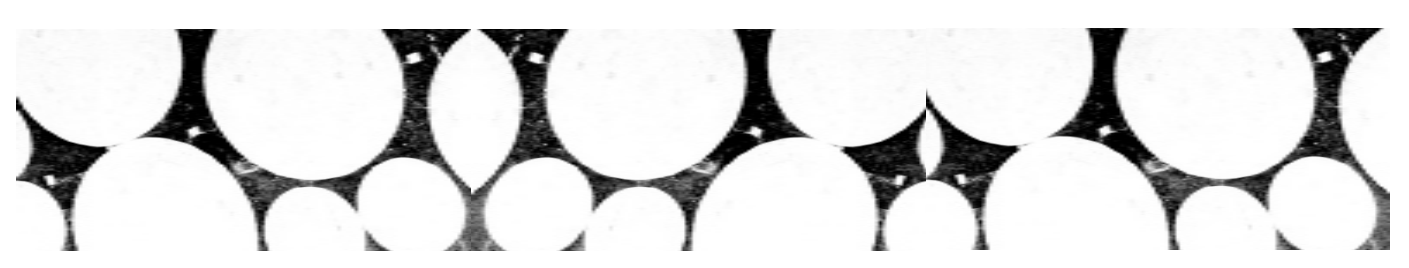

Mônica Benfica Marinho'

MARINHO, M.B. Between functionality and playfulness: condoms in aids prevention campaigns, Interface _ Comunicação, Saúde, Educação, v.4, n.6, 2000.

The starting point for this study is the idea that there are obstacles to the use of condoms. It discusses some of these impediments, namely, the parallel meaning of condoms as something associated with infidelity and promiscuity. These interpretations were analyzed relative to the behavioral model that governs sexual practice and human reproduction, i.e., monogamy. This paper emphasizes that campaigns designed to encourage the use of condoms may be more effective if they dilute the "negative" image connected with these meanings, by associating condoms, for instance, with pleasure and safety, through playful and relaxed advertising.

KEYWORDS: sex behavior; acquired immunodeficiency syndrome; preventive health services.

Este trabalho parte da idéia da existência de impedimentos ao uso da camisinha. Abordou-se alguns desses impedimentos que são as significações marginais como a infidelidade e a promiscuidade que a camisinha encarna. Essas significações marginais foram analisadas em relação a um modelo de comportamento que rege a prática sexual e a reprodução humana - a monogamia. Enfatizou-se que as campanhas, que têm como tema o estímulo ao uso da camisinha, podem alcançar uma maior eficácia ao diluírem a imagem "negativa" emanada dessas significações, associando, por exemplo, a camisinha a prazer e segurança, por meio de spots lúdicos e descontraídos

PALAVRAS-CHAVE: preservativos; síndrome de imunodeficiência adquirida; serviços preventivos; comportamento sexual. 
É inegável que a camisinha, também conhecida como preservativo, "camisa de vênus", Condom, é um meio eficaz para a prevenção da Aids e outras doenças sexualmente transmissíveis, permitindo práticas sexuais com penetração, com menor risco de contaminação. É também um tema sobre o qual debruçamse insistentemente as campanhas governamentais e não governamentais de prevenção da Aids, veiculadas pela tv brasileira desde 1987, que destacam a eficiência da camisinha procurando convencer o telespectador sobre a necessidade de incorporá-la a suas práticas sexuais.

Não se desconhece que as campanhas de prevenção da Aids veiculadas pela televisão têm buscado alcançar uma maior eficácia na sua atribuição de despertar, nos indivíduos, o desejo e, conseqüentemente, o aumento do consumo de um produto tão polêmico. Mas também não se pode deixar de perceber que alguns elementos articulam-se e constituem barreiras, dificultando que as campanhas realizem seu objetivo. Analisam-se, a seguir, alguns desses elementos e como as campanhas que têm como tema o estímulo ao uso da camisinha podem transpor essas barreiras e ser eficazes na promoção de uma imagem desejável, sedutora, da camisinha.

\section{O consumo da camisinha}

Na história do Ocidente, o aparecimento da camisinha não é um fato preciso. Fala-se da sua presença no Egito antigo ${ }^{2}$ e na Roma antiga ${ }^{3}$. Sua primeira descrição escrita data de 1564, quando o italiano Fallopio disse que um envoltório de linho usado sobre o pênis durante o ato sexual impediria a disseminação de doenças. A própria origem da palavra condom ${ }^{4}$ é desconhecida, existindo sobre ela algumas versões (Schiavo, 1996).

Angus McLaren (1997) observa que os preservativos no século XVII eram fabricados de bexiga de animais ou de peles finas. Acrescenta que no século XIX, com o processo de vulcanização da borracha, o preservativo passa a ser produzido em maior quantidade. Mas, mesmo sendo lavado, seco e reutilizado, era considerado de alto custo para as classes baixas, tendo sua utilização limitada. Na década de trinta do século XX, o preservativo passa a ser produzido em látex, material mais confortável que a borracha.

Conforme ressalta o autor, o certo é que seu aparecimento esteve muito mais ligado às doenças sexualmente transmissíveis que à contracepção. Esta, na sua maior parte, ficava a cargo das mulheres que faziam uso, no final do séc. XVII, de esponja e tampões. Odiado por uns e amado por outros, o preservativo, identificado com práticas libertinas, doenças sexualmente transmissíveis e prostituição, teve seu acesso limitado nas relações entre casados. Aliado à simbologia da perversão, o fato de existir uma certa unanimidade de que a contracepção ficasse a cargo das mulheres, corroborava tal impedimento ${ }^{5}$.

Durante a Primeira Guerra Mundial, a camisinha se popularizou com a função de prevenção das doenças venéreas. McLaren reitera que sua associação à prostituição, por oposição ao casamento, ficava assim confirmada. $\mathrm{Na}$ verdade, os métodos masculinos de contracepção, já pouco adotados, iam sendo suplantados pelos métodos femininos. O advento da pílula, e do DIU (Dispositivo Intra-Uterino), intensificou esse processo ${ }^{6}$.

\author{
2 "Fragmentos de \\ arte egípcia antiga, \\ apresentando homens \\ com um envoltório sobre \\ o pênis, parecem ilustrar \\ o uso do preservativo" \\ (Schiavo, 1997, p.10). \\ ${ }^{3}$ Grande parte dos \\ historiadores acreditam \\ que os soldados Romanos \\ foram os primeiros a \\ usar o Condom. Quando \\ confraternizavam com \\ as mulheres do local em \\ longas marchas fora de \\ Roma, os soldados usavam \\ tripa de intestino de ovelha \\ como revestimento para se \\ protegerem contra doenças, \\ a mais notória das quais \\ era a 'Erupção do Monte \\ Vesúvio'". History of the \\ condom, Condom country \\ catalog, http://www. \\ condom.com/ (10/08/97). \\ ${ }^{4}$ A versão mais aceita \\ internacionalmente diz \\ que ela tería originado do \\ vocábulo latino condus, que \\ significa receptáculo. Por \\ sua vez, acredita-se em uma \\ derivação do persa kendu \\ ou kondu, cujo significado \\ literal é vaso comprido de \\ armazenamento, feito do \\ intestino de um animal. \\ A versão mais famosa, no \\ entanto, é a que se refere \\ a um célebre ‘Doutor \\ Condom', médico do século \\ XVII que teria fornecido esse \\ método ao então Rei Carlos \\ II, da Inglaterra. (Schiavo, \\ 1997, p.11).
}


${ }^{5}$ Annie Besant, a primeira defensora da contracepção, que se referia ao preservativo como'usado por homens de caráter dissoluto como prevenção para as doenças sifitílicas e recomendado ocasionalmente como anteparo preventivo' preferia claramente que a mulher retivesse $o$ controle usando a esponja . O pressuposto, pelo menos entre a classe trabalhadora, era o de que o planejamento familiar devia manter-se como responsabilidade da mulher. (McLaren, 1997, p.230).

${ }^{6} \mathrm{Na}$ década de 80 , cerca de $90 \%$ dos casais casados na maioria dos países ocidentais empregavam contraceptivos. Num levantamento internacional dos utilizadores de contraceptivos, verificou se que $33 \%$ tinham sido esterelizados, $20 \%$ empregavam o contraceptivo oral, $15 \%$ o DIU e $10 \%$ o preservativo. (McLaren, 1997, p.285)

${ }^{7}$ Vale conferir dois sites: htpp://www.condomania. com e http://www.durex. com
O surgimento da Aids, na década de oitenta, fez com que a camisinha fosse bastante requisitada, principalmente entre os jovens solteiros. Ela

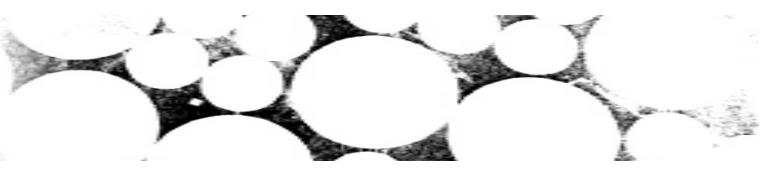
conseguiu uma divulgação estrondosa na mídia. Atualmente, fala-se da "geração camisinha", aquela que desenvolveu sua sexualidade sob a ameaça da Aids. A camisinha é o centro de atenções de sexólogos e psicólogos que, nas colunas de jornais, pregam insistentemente seu uso, principalmente pelos adolescentes, que, aliás, já têm camisinha sob medida. Ela é tema de música, objeto apropriado por designer para suas criações, vendida como coca-cola ou chiclete nas máquinas conhecidas como vending machine, e já pode ser comprada em diversos sabores e cores. Informações sobre ela podem ser encontradas em descontraídos sites na internet ${ }^{7}$. Já virou até selo. Enfim, ela está abundantemente presente nos meios de comunicação, gerando as mais variadas discussões. Mas, por trás dessa aparente visibilidade, permanecem atribuições contraditórias de sentido e valor a esse objeto. Apesar de ter sua capacidade preventiva reconhecida, não há uma correspondência direta entre esse reconhecimento e a prática efetiva de seu uso.

Isso pode ser demonstrado por pesquisas realizadas no Brasil. Um estudo, citado por Schiavo (1997), realizado com homens na faixa etária entre 18 e trinta anos, nas categorias de estudantes universitários, bancários e operários, demonstrou que, dos $75 \%$ de entrevistados que tinham mantido relações sexuais nos trinta dias anteriores à pesquisa, cerca de $29,8 \%$ relataram o uso do preservativo.

Dentre essas categorias, o uso do preservativo, como a principal medida de prevenção das doenças sexualmente transmissíveis e Aids, apareceu primeiro entre os operários, seguidos dos bancários e, finalmente, entre os estudantes universitários. Este dado, segundo o autor, "talvez possa ser explicado pelo fato de que são os operários que recorrem com mais freqüência aos serviços de trabalhadoras sexuais, o que justificaria um uso mais consistente da camisinha" (p.26). Não ser promíscuo e conhecer bem a parceira foram relatados também como meio de prevenção predominante entre os bancários, sendo bem menos referida pelos operários da construção civil (Schiavo, 1997).

Em relação à "imagem pública da camisinha", ela permanece associada a comportamentos sexuais percebidos como promíscuos, irregulares ou desviantes. Já as razões alegadas para seu não uso aparecem como "ter confiança no parceiro"; "ter parceiro fixo"; "não sentir-se à vontade para usá-la"; "não sentir vontade de usá-la"; "estar usando outro método anticoncepcional"; "esquecer de comprá-la ou não tê-la no momento em que ocorre a relação" (Schiavo, 1997, p.32).

Alguns textos publicados no jornal Folha de S.Paulo entre os anos 1995 e 1998, que tratam das dificuldades e barreiras em relação ao uso da camisinha, são ilustrativos:

Pesquisa Nacional sobre Demografia e Saúde realizada este ano pela ONG (Organização Não-Governamental) Bemfam (Sociedade Civil do Bem-Estar Familiar no Brasil) em 800 municípios do Brasil, ouviu 
12.612 mulheres de 15 a 49 anos e 2.949 homens de 15 a 59 anos... Entre os homens, só $4,4 \%$ usam camisinha.

(Folha de S. Paulo, 08/10/96)

A vida íntima de 1.900 homossexuais e bissexuais está sendo rastreada por quatro projetos em São Paulo, Rio de Janeiro e Belo Horizonte. O objetivo é conhecer suas práticas sexuais, saber como se comportam, como pegam o vírus HIV e o que fazem para evitá-lo...Três dos projetos já completaram dois anos. As conclusões preliminares revelam uma espécie de 'roleta-russa' da Aids. Treze participantes pegaram o HIV. A maioria relatou ter se exposto a risco, como a penetração anal sem camisinha e com parceiro desconhecido. Em alguns casos, no entanto, as pessoas disseram ter se descuidado uma vez. Em São Paulo, dois dos três voluntários que pegaram HIV eram cautelosos e tinham parceiros estáveis. No grupo que não se infectou quase $99 \%$ deles são voluntários que tiveram relações desprotegidas com inúmeros parceiros desconhecidos. Cerca de $6 \%$ deles disseram ter tido mais de 21 parceiros em seis meses. (Folha de S. Paulo, 28/11/96)

A "pílula 24h" está causando uma corrida aos consultórios de infectologistas paulistas. Pessoas que mantêm relações sexuais sem camisinha estão procurando seus médicos na manhã seguinte querendo tomar o coquetel anti-Aids para evitar a contaminação. (Folha de S. Paulo, 03/07/97)

Segundo dados da Secretaria da Saúde de São Paulo, adolescentes de 13 a 19 anos só usam camisinha quando têm relações instáveis. Quando têm namorado ou estão apaixonados, eles dispensam o preservativo, revela a secretaria. (Folha de S. Paulo, 05/08/96)

Pesquisa do governo de São Paulo revela que 40\% das mulheres que contraíram Aids em relações heterossexuais têm parceiro fixo. (Folha de S. Paulo, 08/03/95)

Apesar de novos, os adolescentes da geração Aids têm muita informação sobre sexo. Nas entrevistas, eles se apressam em dizer que usam camisinha, que já foram ao ginecologista e respondem sobre sexo oral ou anal sem titubear. Segundo as pedagogas, apesar de dominarem o vocabulário, os adolescentes usam pouco as informações na hora do ato sexual A orientadora educacional de sétima e oitava séries do Colégio Augusto Laranja, Áurea de Oliveira Lima, diz que os medos e tabus acabam contando mais do que as informações no momento da 'transa'. (Folha de S. Paulo, 25/05/97)

Perdi a virgindade há apenas uma semana, com camisinha. Agora, só vamos usar quando der tempo de colocar, senão, tudo bem. Confiamos um no outro, e o teste de Aids que fizemos deu negativo. Sei que se ele me chifrar, vai usar camisinha com a outra. P.O.C., 18 (Folha de S. Paulo, $12 / 05 / 97)$

O novo padrão das vítimas da Aids é de mulheres cada vez mais jovens contaminadas por seus parceiros. Muitas delas monogâmicas, mas vítimas dos companheiros promíscuos. (Folha de S. Paulo, 07/03/98)

É cada vez maior o número de adolescentes grávidas e contaminadas pelo HIV. O aumento de casos de Aids entre adolescentes é, na verdade, um problema mundial. Tanto que o foco da campanha Anti-Aids deste ano a UNAIDS (Setor das Nações Unidas que trabalha com a Aids) são os jovens. Segundo a ONU, das 30 milhões de pessoas vivas infectadas pelo HIV no mundo, pelo menos um terço tem entre 10 e 24 anos. (Folha de

S. Paulo, 03/05/98) 
Mas, que sentido é este que envolve a prática do uso da camisinha em uma teia de contradições, relutâncias e desconfianças? Como compreender que seja tão restrito um uso que responde a uma necessidade de prevenção de doenças e, por que não dizer, de preservação da vida?

Essas indagações levam a uma reflexão a partir de duas importantes questões: primeiro, a necessidade de atribuir-se a esse objeto valores que ultrapassem sua mera funcionalidade, reconhecendo o papel que as instâncias simbólica e imaginária desempenham na prática de seu uso. Segundo, é fundamental atentar para o fato de que o que se constitui como uma das barreiras, talvez a mais importante, ao uso da camisinha é o sentido ainda marginal que ela encarna. Acredita-se que essas questões podem ser mais bem compreendidas a partir da elaboração teórica de Marshall Sahlins (1979), que desenvolve a idéia de cultura como dimensão simbólica da vida humana, e de Castoriadis (1982), que explora a dimensão social do imaginário.

Uma significação marginal

Quando faz uma crítica à idéia de que as culturas humanas são formuladas a partir da atividade prática e do interesse utilitário, Marshall Sahlins (1979, p.227), afirma que

nenhuma forma cultural pode ser interpretada a partir de um grupo de 'forças materiais', como se o cultural fosse a variável dependente de uma inevitável lógica prática (...) nenhuma explicação funcional por si só é suficiente, já que o valor funcional é sempre relativo a um esquema cultural.

Tomando como base a afirmação do autor, pode-se acrescentar que uma lógica funcional tem como referencial o mundo destinado a produzir objetos, satisfazer as necessidades primárias dos homens e assegurar sua sobrevivência. Na lógica funcional, esse mundo constitui-se, portanto, como hierarquicamente definidor das instâncias "ideais" ou, como se pode chamá-las, simbólicas e imaginárias.

Ao se atentar para o fato de que os homens sobrevivem, mas sobrevivem de formas diferentes, a relação produção e satisfação de necessidade passa a estar estruturada por algo que não se dá a partir de uma lógica "da razão prática", mas de um universo simbólico que faz do mundo dos homens um mundo de significação. Assim, a hierarquia inicialmente estabelecida, na qual o mundo material determina o mundo ideal, deixa de ter sentido.

Tendo como referência essas reflexões, ao se tomar a camisinha como um objeto (produto) que simplesmente tem como função definida a satisfação de determinadas necessidades, como a contracepção e a prevenção das doenças sexualmente transmissíveis, está-se definindo essa relação a partir de uma lógica utilitária ou funcional. Mas, ao se buscar compreender essa relação para além de um encadeamento sem falhas entre meios e fins, leva-se em conta a presença de uma instância - não redutível a um esquema funcional/utilitário -, que é a dimensão simbólica da vida humana. 
Se, de fato, a prática do uso da camisinha faz parte de um sistema cultural, portanto simbólico, está permanentemente regida por um sistema de significação cultural do objeto. E, como lembra Sahlins (1979), "nenhum objeto, nenhuma coisa é ou tem movimento na sociedade humana, exceto pela significação que os homens lhe atribuem" (p.189).

Essas questões podem ser ampliadas com Castoriadis (1982), quando mostra como o mundo social-histórico se entrelaça com o simbólico. Os atos sejam

reais, individuais ou coletivos - o trabalho, o consumo, a guerra, o amor, a natalidade - os inumeráveis produtos materiais sem os quais nenhuma sociedade poderia viver um só momento, não são (nem sempre, não diretamente) símbolos. Mas uns e outros são impossíveis fora de uma rede simbólica (p.142).

Da mesma maneira que o componente racional/funcional é questionado como dominante da experiência humana por um esquema simbólico (captar o simbolismo de uma sociedade é captar as significações que esta carrega), este não esgota as possibilidades humanas, pois subsiste aí, de acordo com o autor, um componente essencial que é o imaginário. Trazendo essas reflexões para o que interessa - as significações do uso da camisinha -, pode-se dizer que em torno de um núcleo funcional (a camisinha tem a função de prevenção), cristalizam-se sentidos não racionais, ou imaginários. Portanto, as campanhas publicitárias de prevenção da Aids, que trabalham apenas com apelos racionais utilitários, desconsideram que a camisinha, apesar de ter uma função de prevenção, carrega uma significação outra pela qual as pessoas podem ser reconhecidas como "infiéis", promíscuas ou doentes. Estes sentidos só existem em relação ao modelo de comportamento dominante, que rege a prática sexual e a reprodução humana, que é a monogamia ${ }^{8}$. Este modelo não se organiza somente na ordem do funcional, do simbólico, mas também do imaginário. Isto quer dizer, de acordo com Castoriadis, que o mundo social-histórico se articula em função de um sistema de significações que são "imaginárias".

Desse modo, é como contraponto de um modelo monogâmico que a camisinha ganha uma significação "marginal". Nesse modelo, a fidelidade dos cônjuges é exigida, a multiplicidade de parceiros é condenada. Como coloca Adam Phillips (1997), "na verdade contrastamos a monogamia não com a bigamia ou com a poligamia, mas com a infidelidade, porque se trata de nossa religião secular" (p.10). De acordo com o autor, a infidelidade é o problema que é porque assumimos a monogamia como algo indiscutível.

O uso da camisinha questiona esse modelo, traz à tona o subterrâneo, o que escapa ao discurso instituído sobre as formas das relações sexuais. "Nem todo mundo acredita na monogamia, mas todos vivem como se acreditassem. Todos têm consciência de estar mentindo ou querendo dizer a verdade quando estão em jogo a verdade e a lealdade ou a fidelidade" (Phillips, 1997, p.01).

Mas novos sentidos emergem e ganham força. E esses sentidos positivos vêm ganhando corpo em correspondência à fragilização da monogamia
${ }^{8} \mathrm{Na}$ mesma perspectiva das reflexões de Castoriadis, faz-se, aqui, referência à monogamia como uma instituição que remete a um "sentido organizador" de atos relativos à prática sexual, e "que faz levantar no meio do campo do possível a marcha que separa o lícito do ilícito, que cria um valor" (McLaren, 1997, p.186). Ela organiza, enfim, um sistema de significações, dando à pratica do uso da camisinha determinados significados. 
${ }^{9} \mathrm{O}$ tema da multiplicidade de parceiros foi abertamente abordado em campanhas como a do "Bráulio" ("...se você transa um dia com uma um dia com outra tem que usar a camisinha"); campanha da MTV veiculada em 1997 ("...você pode transar com quantas pessoas você quiser, quantas tiver vontade, mas a camisinha tem que estar sempre à mão"); ou a campanha do Grupo de Apoio e Prevenção à Aids da Bahia veiculada em 1996/97 (“..por amor a você, por amor ao seu parceiro use camisinha"). instituída como modelo inquestionável, um processo que se intensificou com o advento da Aids. A doença trouxe à tona - e a mídia teve um papel preponderante nesse processo - o fato de que pessoas que acreditavam viver uma relação monogâmica estavam sendo contaminadas pelo vírus da Aids via relação sexual. As campanhas começaram a abordar a questão por meio do discurso da possibilidade da multiplicidade de parceiros ${ }^{9}$; assim também o fizeram jornais, revistas e publicações de organizações que trabalham com a questão da Aids. Comportamentos que antes permaneciam na sombra, e dos quais pouco se falava, agora têm que ser encarados como reais e presentes. A significação marginal da camisinha, então, acompanha essas mudanças e vai incorporando outros significados. Ela está passando a significar a possibilidade de diálogo e de discussões abertas, em todos as formas de relações que impliquem envolvimento sexual. Não se pode dizer, ainda, que seja um sentido dominante, mas é inquestionável que permeia o comportamento de vários grupos sociais.

Não se pode negar também a tendência de uma nova moral sexual, baseada em comportamentos monogâmicos e estáveis. Essa nova moral sexual distancia-se daquele modelo de comportamento sexual coercitivo porque, segundo Lipovetsky (1989), quando se privilegia a monogamia, faz-se não por uma economia monástica de autonegação, mas por um processo autoorganizador individualista. A fidelidade, de acordo com o autor, está ligada "a um desejo mais amplo de segurança e estabilidade emocional nas sociedades cada vez mais móveis, competitivas, sem orientação fixa (...). A celebração da fidelidade responde a esta civilização angustiada, introduz a continuidade onde tudo é confusão" (p.10).

Nas malhas do lúdico

Como vimos, uma das dificuldades encontradas para se instituir o uso da camisinha é a atribuição de uma significação marginal ao objeto e essa dificuldade pode ser diluída ao se lhe atribuir qualidades que se contrapõem a essa significação inicial. A questão, então, é: como isso pode ser elaborado e ganhar expressão nas campanhas de prevenção da Aids veiculadas pela tv?

Pelas reflexões elaboradas até o momento, pode-se concluir que produzir campanhas incitando o uso da camisinha é um procedimento importante. Mas é fundamental se atentar para o fato de que uma das barreiras - talvez a mais importante - para seu uso, é o sentido ainda marginal que ela encarna. Por conseguinte, dar atribuições de sentido a esse objeto que ultrapassem o mero valor preventivo (pode-se agregar à camisinha valores como erotismo, sensualidade, segurança), é uma tarefa absolutamente necessária.

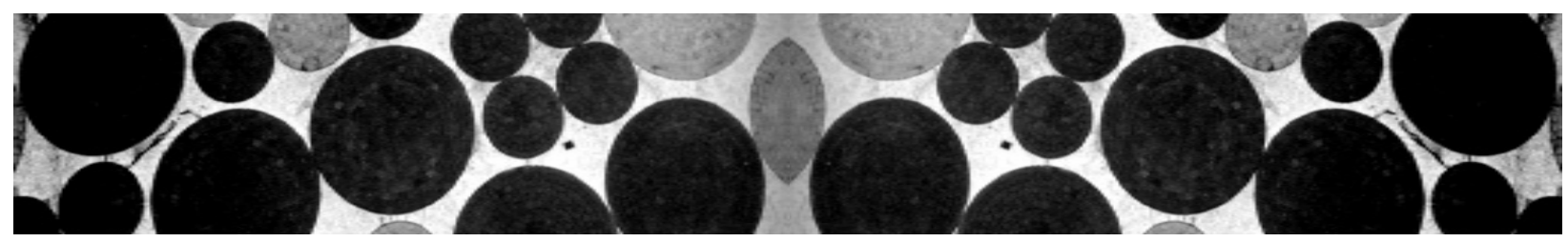

fevereiro, 2000 
É possível falar em tornar visíveis determinados atributos da camisinha que possam conduzir a um processo de identificação do espectador com esse objeto, pela exaltação de suas qualidades e das qualidades daqueles que fazem uso dele. Maffesoli (1996) fala da força desse "instinto mimético", que faz com que "tanto no que diz respeito à maneira de se vestir, quanto aos hábitos de linguagem, dos costumes sexuais ou até leitura ou as modas do

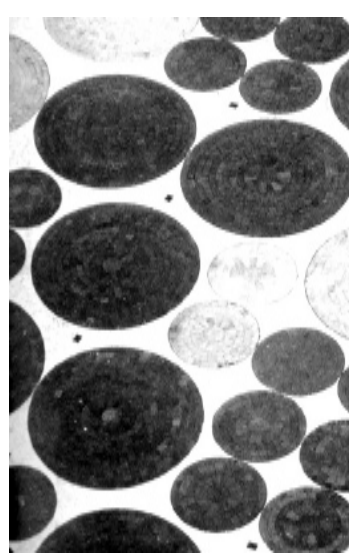
pensamento, se esteja diante de uma seqüência de conformismos mais ou menos cambiantes" (p.180).

Ao proporem o uso da camisinha sobre o plano da morte, da dor, da tristeza - "use camisinha, assim de Aids você não morre" -, as campanhas criam um terreno propício para a rejeição. Contudo, existe a possibilidade de se envolver o negativo em uma afirmação ou compensação, pois uma imagem afirmativa "oblitera a fronteira inaceitável entre sujeito e objeto; praticamente acaba por negar que exista um exterior inassimilável ou uma alteridade radical" (Bougnoux, 1994, p.137). Uma proposta afirmativa e prazerosa - "Sexo seguro é mais gostoso" -, parece ser o modo capaz de convocar, de promover uma identificação entre espectador e produto.

O resultado de uma pesquisa realizada com adolescentes (Marinho, 1999) vem endossar essa idéia. A pesquisa buscou descrever como um determinado público acolhe diferentes apelos de um produto que tem tarefa tão espinhosa como a prevenção da Aids, pelo estímulo ao uso da camisinha. Objetivou-se, com esse procedimento, obter alguns dados que pudessem contribuir para alargar a discussão sobre a eficácia das estratégias das campanhas de prevenção da Aids, e, de modo específico, ampliar as discussões sobre a idéia de que estratégias de sedução, visando a empatia do público nas campanhas de prevenção, parecem ter um maior alcance do que estratégias de produção do medo, de evidência da morte, da restrição e da falta, mesmo tratando-se de campanhas como essas, que lutam contra a corrente de uma possível morte das pessoas contaminadas.

Foram apresentadas para os adolescentes três peças de campanhas de três diferentes instituições:

. Campanha "Bráulio"- Campanha do Ministério da Saúde, produzida pela Master, composta de quatro peças, veiculada no ano de 1995. Esta campanha aborda diálogos entre um homem e seu órgão genital, que recebeu o nome de "Bráulio". A escolha dessa denominação para a genitália foi alvo de intensos protestos, por parte daqueles que tinham esse nome e teve, como conseqüência, a suspensão de sua veiculação, que só foi retomada quando fizeram modificações e a genitália passou a não ter denominação alguma. Essa polêmica gerou infindáveis matérias na mídia em geral, terminando por popularizar a campanha. Ela recebeu várias críticas de vários setores da sociedade. Foi considerada uma campanha de mau gosto, que tratava a Aids como brincadeira, e que centrou a atenção muito mais na discussão do "Bráulio" propriamente dito do que na questão da prevenção da doença. 
- Campanha "Depoimentos" - Campanha do GAPA/BA (Grupo de Apoio à Prevenção à AIDS da Bahia) produzida pela Link, composta de cinco peças, veiculada no ano de 1996 e parte do ano de 1997, no Estado da Bahia. Essa campanha foi produzida como uma forma de oposição à campanha do "Bráulio", acusada de tratar a Aids como brincadeira. A peça mostra depoimento de uma mulher soropositiva que contraiu o vírus de seu companheiro.

. Campanha de prevenção da Aids - Campanha da MTV produzida pela MTV, composta de cinco peças e veiculada no ano de 1997. Essa campanha, dirigida a adolescentes, aborda o uso da camisinha em diversas práticas sexuais - sexo entre pessoas do mesmo sexo, sexo em grupo, relações consideradas estáveis -, de forma aberta e lúdica. Diferentemente das duas anteriores, sua veiculação foi restrita ao canal da MTV, como acontece com os produtos da emissora.

De cada campanha, foi selecionada uma peça que obedeceu ao critério do tema veiculado. As peças das campanhas veiculadas na tv, de forma geral, têm três temas recorrentes: formas de contaminação via sexual e o uso da camisinha; formas de contaminação via sanguínea; e a solidariedade ao portador do vírus e doente de Aids.

Optou-se por trabalhar com peças que tivessem como tema formas de contaminação via sexual e, dentro desse tema, a peça que abordasse a multiplicidade de parceiros e o uso da camisinha. Essa escolha justifica-se pela presença deste, que pode ser chamado, sub-tema desde as primeiras campanhas - a multiplicidade de parceiros. Esse assunto foi abordado em um primeiro momento na forma de apelos à diminuição de parceiros e à fidelidade. Nas campanhas mais recentes, os apelos não são mais de restrição, mas de condicionamento desse modelo de comportamento sexual ao uso da camisinha. A título de identificação por parte do universo pesquisado, as peças foram intituladas de "Bráulio" (Ministério da Saúde), "Mulher" (GAPA/BA) e "Jovens" (MTV).

O fator considerado preponderante para a escolha de peças que abordassem a contaminação por via sexual é que o tema propiciasse a discussão da questão da instituição da monogamia e fidelidade, uma das maiores barreiras para o uso da camisinha.

O resultado da pesquisa apontou a peça "Bráulio" como a preferida entre os entrevistados, seguida da peça "Jovens" e por último "Mulher". Foram as seguintes as respostas dos entrevistados quanto às razões que os levaram a gostar mais do "Bráulio": por ser engraçado (39,13\%); porque as pessoas aprendem a se prevenir rindo e brincando (26,09\%); por incentivar a usar a camisinha (23,91\%); porque inovou (13,04\%); porque vai direto ao assunto $(4,35 \%)$; porque conscientiza (4,35\%); porque disse que "sexo seguro é sexo gostoso" (4,35\%); porque é mais excitante ( $2,17 \%)$; porque mostra que não é complicado lidar com a Aids (2,17\%); porque é mais real $(2,17 \%)$; porque é fácil de ser entendido $(2,17 \%)$.

Em relação à peça "Jovens", a preferência deu-se porque: tem mais relação com os jovens (38,89\%); diz que pode ter vida sexual ativa $(13,89 \%)$; tem ação e mostra que para fazer sexo tem que ter responsabilidade e respeito $(13,89 \%)$; incentiva a usar a camisinha (13,89\%); é fácil de ser entendido $(11,11 \%)$; 
vai mais direto ao assunto ( $8,33 \%)$, conscientiza $(2,78 \%)$; mostra que pode acontecer com qualquer um (2,78\%).

Quanto à peça "Mulher", a preferência se explica porque: mostra que, mesmo com o parceiro, deve usar a camisinha $(17,86 \%)$; é mais real $(17,86 \%)$; conscientiza (14,29\%); incentiva a usar a camisinha (10,71\%); mostra que pode acontecer com qualquer um (10,71\%); é fácil de ser entendido $(10,71 \%)$; a pessoa assume que tem o vírus da Aids ( $7,14 \%)$; é mais sério $(3,57 \%)$; choca mais $(3,57 \%)$.

Considerando-se as justificativas das preferências das peças, é possível afirmar que motivos não racionais alcançaram, entre os adolescentes, um maior índice na preferência. Ser engraçado, ter mais relação com os jovens, ensinar a prevenir rindo e brincando foram os itens que alcançaram maiores índices na justificativa dos entrevistados e referem-se aos filmes "Bráulio" e "Jovens". Estas peças contrastaram com a peça "Mulher" que lançou mão de apelos mais sérios, racionais, e ficou em último lugar na preferência dos adolescentes.

As peças Bráulio" e "Jovens" guardam em comum uma estrutura discursiva, visual e sonora, caracterizada pela afirmação, pelo hedonismo, pelo ludismo e pela ação; elementos totalmente ausentes da peça "Mulher".

Uma questão que deve ser destacada é a de que lançar mão de uma estética do lúdico, do riso, para dar forma às campanhas, não é um procedimento consensual entre instituições que trabalham com a prevenção da Aids e tampouco com o público. Uma posição que acolhe os formatos que apelam para o terror e o medo está também presente no universo do espectador.

A peça "Mulher" apresenta uma economia monástica em relação à plasticidade audio-visual e, nas entrevistas, foi indicada como a peça que gerou medo de contágio pelo vírus da Aids, que condenou a prática de múltiplas parcerias, que associou as práticas sexuais à doença.

Os que acreditam que a utilização de elementos aterrorizantes, "sérios", são mais eficientes para promover a conscientização e, conseqüentemente, mudança de comportamento, devem indentificar-se com a peça "Mulher". Poder-se-ia, então, supor que a estrutura fílmica que caracteriza "Mulher" estaria mais apta a promover a conscientização do espectador e conduzi-lo ao uso efetivo da camisinha. Esse procedimento, no entanto, deixa de lado algumas questões que, ao serem negligenciadas, impõem o risco de se trilhar por caminhos inconsistentes.

A consciência da necessidade de usar a camisinha não implica que a prática de seu uso deva ocorrer, uma vez que pesquisas mostram que há uma enorme distância entre um grau avançado de conhecimento em relação à Aids e à necessidade do uso da camisinha e comportamentos que envolvam menor risco. Por terem um maior poder de atração, talvez as campanhas possam incentivar a mudança de comportamento pela via da sedução, da convocação, do estímulo dos desejos, "espírito" presente nas peças produzidas pela MTV no Brasil e que exploram o ludismo, o prazer. Nelas, a possibilidade de contato sexual nunca é negada, mas tratada de forma que ele possa ser mais interessante quando se usa a camisinha, levando em consideração um estilo hedonista que atua no campo social. 
${ }^{10}$ Um bom exemplo é um das peças de uma campanha da MTV, veiculada durante $\mathrm{o}$ ano de 1997, que mostra que uma mulher não submissa é aquela que exige o uso da camisinha pelo parceiro.
Trata-se, aqui, de insistir no fato de se reconhecer que o estímulo do desejo dos indivíduos pela camisinha não deve limitar-se ao seu caráter meramente preventivo. Deve-se buscar associar, à prevenção, valores socialmente reconhecidos, respeitados e desejados ${ }^{10}$, o que pode ser feito explorando um núcleo afirmativo com spots criativos e lúdicos.

\section{Referências bibliográficas}

BOUGNOUX, D. Introdução às ciências da informação e da comunicação. Trad.G. J. Freitas. Petrópolis: Vozes, 1994.

CASTORIADIS, C. A instituição imaginária da sociedade. Trad. G. Reynaud. Rio de Janeiro: Paz e Terra, 1982.

LIPOVETSKY, G. O império do efêmero: a moda e seu destino nas sociedades modernas. Trad. M. L. Machado. São Paulo: Companhia das Letras, 1989.

McLAREN, A. História da contracepção: da antiguidade à actualidade.

Trad. T. Perez. Lisboa: Terramar, 1997.

MAFFESOLI, M. No fundo das aparências. Trad. B. H. Gurovitz. Petrópolis: Vozes, 1996.

MARINHO, M.B. Da ameaça à sedução: um estudo sobre as campanhas de prevenção da Aids veiculada pela televisão. Salvador, 1999. 132p. Dissertação (Mestrado). Pós-Graduação em Comunicação e Cultura Contemporâneas, Universidade Federal da Bahia

PHILLIPS, A. Monogamia. Trad. C. Sussekind. São Paulo: Companhia das Letras, 1997.

SAHLINS, M. Cultura e razão prática. Rio de Janeiro: Zahar, 1979.

SCHIAVO, R. M. Preservativo masculino: hoje mais necessário do que nunca! Brasília: Ministério da Saúde, 1997.
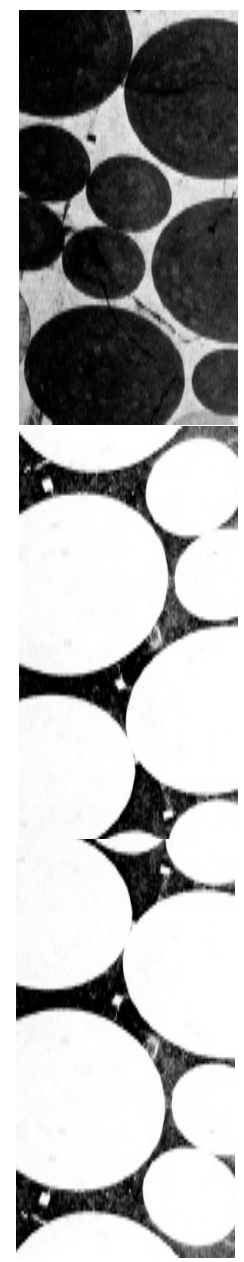

MARINHO, M.B. Entre lo funcional y lo lúdico - el condón en las campañas de prevención del SIDA, Interface Comunicação, Saúde, Educação, v.4 , n.6, 2000.

Este trabajo parte de la idea de la existencia de obstáculos al uso del condón. Se abordaron algunos de esos obstáculos que son las significaciones marginales como la infidelidad y la promiscuidad que el condón representa. Esas significaciones marginales fueron analizadas en relación a un modelo de comportamiento que guía la práctica sexual y la reproducción humana: la monogamia. Se enfatizó que las campañas, que tienen como tema el estímulo al uso del condón, podrían tener más eficacia si borrasen la imagen "negativa" surgida de esas significaciones, asociando, por ejemplo, el condón a placer y seguridad, mediante spots lúdicos y desembarazados.

PALABRAS CLAVE: condón; SIDA; campaña; prevención. 


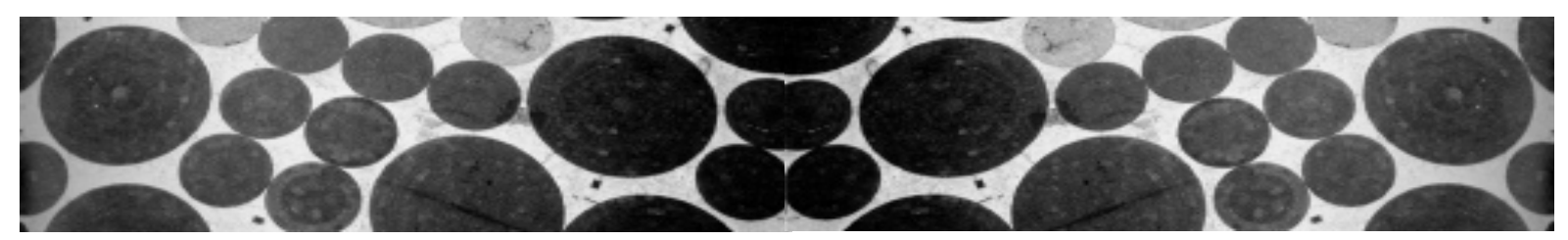

Interface - Comunic, Saúde, Educ 6 